\title{
Celebrating the International Year of Light in Michigan
}

\section{Anca Sala, Elizabeth F. Dreyer, Cynthia Aku-Leh, Timothy Jones, John Nees, et al.}

Anca L. Sala, Elizabeth F. C. Dreyer, Cynthia Aku-Leh, Timothy Jones, John A. Nees, Arlene Smith, "Celebrating the International Year of Light in Michigan," Proc. SPIE 9946, Optics Education and Outreach IV, 994602 (27 September 2016); doi: 10.1117/12.2236490

EDent: SPIE Optical Engineering + Applications, 2016, San Diego, California, United States 


\title{
Celebrating the International Year of Light in Michigan
}

\author{
Anca L. Sala*a, Elizabeth F. C. Dreyer ${ }^{\mathrm{b}}$, Cynthia Aku-Leh ${ }^{\mathrm{c}}$, Timothy Jones ${ }^{\mathrm{d}}$, John A. Nees ${ }^{\mathrm{b}}$, Arlene \\ Smith $^{\mathrm{e}}$ \\ ${ }^{a}$ College of Engineering, Baker College, Flint, MI, USA 48507; ${ }^{b}$ Optics and Photonics Laboratory, \\ University of Michigan, Ann Arbor, MI, USA 48109; ' ISCIENCES, L.L.C., Ann Arbor, MI, USA \\ 48103; ${ }^{\mathrm{d} C o l o r S p r i t z, ~ A n n ~ A r b o r, ~ M I, ~ U S A ~ 48103 ; ~}{ }^{\mathrm{A}}$ Avo Photonics, Inc., Horsham, PA, USA 19044
}

\begin{abstract}
The 2015 International Year of Light created a wonderful opportunity to bring light and optics events and activities to people of all ages and occupations in Michigan. A large spectrum of events took place; from events held in schools, colleges, and universities targeting various groups of students, to events associated with festivals attended by large crowds. The latter included the Ann Arbor Summer Festival held in June and the Flint Back-to-the-Bricks Festival in August. All events included interactive activities where participants learned hands-on about optics and photonics phenomena and applications. Original demonstrations and kits were developed by the Ann Arbor OSA Local Section and the Optics Society at the University of Michigan, the joint OSA/SPIE student chapter, for use during the events. The activities were funded through the student chapter's SPIE grant for IYL outreach events and corporate sponsorships. Under the name Michigan Light Project, these groups along with local technology enthusiasts and science clubs delivered several events across Michigan. Other events took place throughout the year in Mid-Michigan through the efforts of faculty and students in the Photonics and Laser Technology program at Baker College of Flint. The outreach events targeted students in K-12. Teachers, counselors, and parents also learned about the importance of optics and photonics in society. The activities developed will continue this year and in the future. The paper will provide details on the completed events and activities along with tips for implementing similar activities and outreach partnerships in other areas.
\end{abstract}

Keywords: Photonics outreach activities, optics enrichment programs, photonics demonstration kits, International Year of Light, Michigan Light Project

\section{INTRODUCTION}

The 2015 International Year of Light served as an important catalyst for optics-related outreach activities throughout the State of Michigan during 2015. The uniqueness of this event brought together people of all ages and occupations in Michigan. Recognizing the opportunity of this year, multiple optics-related groups worked together for 16 events that directly affected over 1500 people. A large spectrum of events took place; from events held in schools, colleges, and universities targeting various groups of students, to events associated with festivals attended by large crowds.

Sections 2 and 3 provide background on the groups involved in Michigan and their processes for developing activities. Section 4 details specific information about the larger events along with their estimated impact on the community. Section 5 provides recommendations for future projects and suggestions on how to implement collaborations like this in other communities. Finally, section 6 provides conclusions.

\section{BACKGROUND: MICHIGAN LIGHT PROJECT}

\subsection{Organizations Involved}

The Michigan Light Project formed in October 2014 as a collaboration between the student chapter of SPIE and OSA at the University of Michigan (the Optics Society at the University of Michigan) and the OSA Local Section (Ann Arbor OSA). Through advertising on the university calendar, additional collaborators were added. In late spring of 2015, the Student Astronomical Society at the University of Michigan joined the Michigan Light Project to plan light-based events for the remainder of 2015 .

\subsection{Fundraising}

Fundraising for the IYL events was done primarily through the Optics Society at the University of Michigan (OSUM). In later 2014, OSUM applied for and was awarded funding from the SPIE International Year of Light Activity Grant and 
the OSA International Year of Light Education Outreach Grant. Additional funding was sought from corporate sponsors. Members of the Michigan Light Project reached out to local optics companies through Mi-Light, the Michigan Photonics Cluster ${ }^{4}$. By having a clear plan for the activities and the proposed benefits to the companies, the Michigan Light Project secured three corporate sponsorships.

\subsection{Development of Kits and Activities}

The outreach activities implemented by the Michigan Light Project were a combination of new ones designed for the International Year of Light as well as classic existing activities. A summary of these activities is shown below. Each activity is classified as a demonstration, consumable activity, and/or interactive activity. Demonstrations are activities run by a volunteer that demonstrate an idea or concept and do not involve audience input. Consumable activities are activities where a component of the activity is either consumed during the activity or given away to participants after the activity. Interactive activities are activities that depend on a high level of participation from the audience.

Table 1. Summary of activities. SAS = Designed by Student Astronomical Society

\begin{tabular}{|c|c|c|}
\hline Activity Name & Activity Type & Source \\
\hline Outdoor Holography & Consumable & Original design \\
\hline Pinky-powered Photons & Consumable & Original design \\
\hline Microscopy & Consumable & Purchased \\
\hline Solar-powered Junk & Interactive & Original design \\
\hline Laser Communication & Demonstration & Standard activity \\
\hline UV Fluorescence & Demonstration & Standard activity \\
\hline Solar Telescope & Interactive & SAS \\
\hline Projection Pyramid & Demonstration & Purchased \\
\hline Diffraction and Color Filters & Demonstration & SAS \\
\hline Spectroscopy & Interactive & SAS \\
\hline Polarized Light Art & Consumable & Standard activity \\
\hline Total Internal Reflection & Demonstration & Standard activity \\
\hline
\end{tabular}

The outdoor holography and pinky-powered photon activities are detailed in companion proceedings to this paper. Microscopy involved purchasing jewelers' microscopes and encouraging participants to examine leaves, bugs, and other interesting samples. Interested participants could take the microscopes home. Solar-powered junk was a collection of solar panels and motors. Bright sunlight or a work light causes the devices to move.

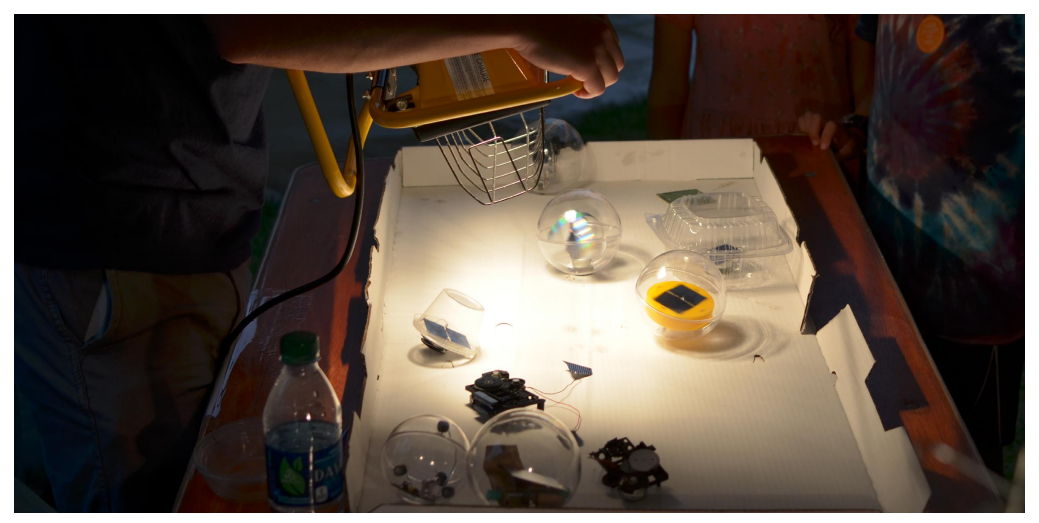

Fig. 1. Solar-powered junk during the Ann Arbor Summer Festival, 30 June 2015.

\footnotetext{
${ }^{*}$ Modification of kit available from LitiHolo (www.litiholo.com)
} 
Laser communication involves sending music over laser light through analog modulation of the laser beam. UV fluorescence demonstrates the ability of materials to 'change color' under UV light. Some materials we used were tonic water and vitamin B. Solar telescope was a telescope with a sun filter. The projection pyramid is a 3D acrylic pyramid that allows the user use a phone or tablet and 'project' a 3D image. SAS provided two activities (color filters and spectroscopy), which examined how light could be composed of multiple colors. Polarized light art uses Polaroid and a birefringent material (packing tape or a plastic fork) to create art.

\section{BACKGROUND: BAKER COLLEGE OF FLINT}

Baker College of Flint introduced a new Associate level program in Photonics and Laser Technology in fall 2013. The program prepares technicians to work in the growing photonics industry in Michigan, as well as throughout the US. Details about the program curriculum can be found in a previous paper ${ }^{1}$. Since the program started, it produced several graduates who are all currently employed in the industry.

Two-year college programs of study in photonics are relatively few throughout the country. The introduction of such a program at Baker College was the synergistic result of several factors. The first was having a faculty member with strong background in photonics being interested in starting such a program to satisfy an existing unmet need for photonics technicians. Researching the status of similar programs, she connected with OP-TEC ${ }^{2}$, the National Center for Optics and Photonics Education, supported by the National Science Foundation's Advanced Technological Education ${ }^{3}$ (NSF ATE) program.

OP-TEC has been in existence for more than 10 years now and has created a wealth of resources that can be used at no cost for developing photonics programs by colleges in the US. Among the valuable resources available from OP-TEC are textbooks for optics and photonics foundation courses, which were especially developed for technicians. These are very useful for two-year programs, as the vast majority of the published optics and photonics textbooks are for senior undergraduate and graduate level courses. Other resources available from OP-TEC include faculty training and help with laboratory equipment.

A third factor was the formation in late 2012 of the Michigan Photonics Cluster, Mi-Light ${ }^{4}$, a non-profit organization promoting the photonics industry in the state. Baker College of Flint is a founding member of the organization and has benefitted from its support and collaboration from the beginning. Finally, Baker College of Flint applied for and was awarded an NSF ATE grant to develop and implement the photonics program. The grant ran from 2013 to 2016 and had several objectives that were fully achieved. These focused on developing the program curriculum, creating a fullyequipped optics and photonics laboratory, training faculty to teach photonics courses, performing outreach activities to K-12 students, and educating a number of college students to become photonics technicians.

\section{IYL EVENTS AND ACTIVITIES}

Although this is by no means a comprehensive list of all of the IYL events and activities in Michigan during 2015, this provides a sampling of the diverse activities we strove to undertake. Subsection 4.1 provides a summary of the activities with the subsequent subsections detailing some of the more complex events.

\subsection{Summary of Events}

Table 2. Summary of IYL Events.

\begin{tabular}{|c|c|c|c|}
\hline Event Name & Location & Date & Audience Estimate \\
\hline Mount Morris Middle School Visit & Baker College, Flint, MI & 6 Mar 2015 & 40 eighth grade students \\
\hline Carman-Ainsworth Middle School Visit & Baker College, Flint, MI & 20 Mar 2015 & 50 eighth grade students \\
\hline Dryden Middle School Visit & Baker College, Flint, MI & 8 May 2015 & 50 eighth grade students \\
\hline Family STEM Night & $\begin{array}{c}\text { Grand Blanc Elementary } \\
\text { School District }\end{array}$ & 1 Jun 2015 & $\begin{array}{c}30 \text { elementary school students } \\
\text { and families }\end{array}$ \\
\hline Ann Arbor Summer Festival & Ann Arbor, MI & 30 Jun 2015 & 200 children + parents \\
\hline $\begin{array}{c}\text { High School "Explore Engineering and } \\
\text { Technology" Summer Camp }\end{array}$ & Baker College, Flint, MI & $\begin{array}{c}\text { 6-10 Jul } \\
2015\end{array}$ & $\begin{array}{c}\text { 25 students entering } \\
\text { grades 9-12 }\end{array}$ \\
\hline \multicolumn{2}{|c}{} & &
\end{tabular}




\begin{tabular}{|c|c|c|c|}
\hline Event Name & Location & Date & Audience Estimate \\
\hline Metro Youth Day & Belle Isle, Detroit, MI & 15 Jul 2015 & $\begin{array}{l}300+\text { middle school and high } \\
\text { school students }\end{array}$ \\
\hline $\begin{array}{l}\text { Middle School "Robotics and } \\
\text { Photonics" Summer Camp }\end{array}$ & Baker College, Flint, MI & 20-24 Jul 2015 & $\begin{array}{c}45 \text { students entering grades } 6- \\
8\end{array}$ \\
\hline EECS Electrify - Light it Up & $\begin{array}{l}\text { Univ. of Mich., } \\
\text { Ann Arbor, MI }\end{array}$ & 20-25 Jul 2015 & 30 high school students \\
\hline Back to the Bricks Festival & Flint, MI & 15 Aug 2015 & 500 people $(20 \% 50$ yro +$)$ \\
\hline NSF Wonders of Light & Washington, DC & 12 Sep 2015 & 150 children + parents \\
\hline EECS Family Night & $\begin{array}{l}\text { Univ. of Mich., } \\
\text { Ann Arbor, MI }\end{array}$ & 25 Sep 2015 & 100 people, all ages \\
\hline Kensington Astronomy at the Beach & $\begin{array}{l}\text { Kensington Metro Park, } \\
\text { Milford, MI }\end{array}$ & 26 Sep 2015 & 80 children + adults \\
\hline 150 Years of Maxwell's Equations & $\begin{array}{l}\text { Univ. of Mich., } \\
\text { Ann Arbor, MI }\end{array}$ & 20 Nov 2015 & $\begin{array}{c}100 \text { college students }+ \\
\text { professionals }\end{array}$ \\
\hline Almont Middle School Visit & Baker College, Flint, MI & 20 Nov 2015 & 140 eighth grade students \\
\hline Dicken Elementary Visit & Ann Arbor, MI & 22 Mar 2016 & 20 first grade students \\
\hline
\end{tabular}

\subsection{Ann Arbor Summer Festival}

The Ann Arbor Summer Festival (A2SF) is a three-week music and arts festival in Ann Arbor, MI. It offers dozens of performances, activities, exhibitions, and screenings representative of the best in music, dance, comedy, film, circus and street arts, and family entertainment. One family-centric activity of A2SF is their KidZone, which is a tent at the main festival location where a different organization organizes an activity each night of the festival. The Michigan Light Project sponsored one such event on 30 June 2015 from 5 PM to 8 PM and advertised light related activities.

Our advertisement in the A2SF bulletin read: "Dive into the Michigan Light Project for an exploration of light! Zoom in on the microscopic universe around you, capture a 3-D hologram, and take home an LED energy harvester. Join us to celebrate the U.N. sponsored 2015 International Year of Light, in which more than 100 partners from more than 85 countries are doing activities that highlight the importance of light and optical technologies in our lives, for our futures, and for the development of society."

We ran 10 different activities - 6 originals from the Michigan Light Project and 4 existing activities from the Student Astronomical Society. They were very well received by the festival-goers. We had 20 volunteers from the Optics Society at the University of Michigan, the Ann Arbor OSA, the Student Astronomical Society, and from the community at large.

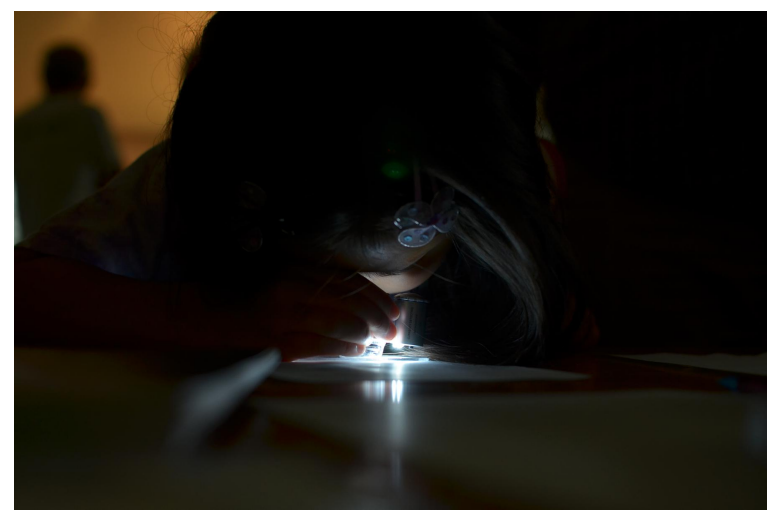

Fig. 2. Young girl examining a sample using a microscope during the Ann Arbor Summer Festival, 30 June 2015. 


\subsection{Baker College of Flint Outreach Events}

The International Year of Light 2015 fit very well with all the activities taking place at Baker College as the first group of college students was going through the new program. The enthusiasm of faculty and students extended over several areas: the first time teaching and learning of these exciting subjects, using the new lab equipment, and spreading the message about this very interesting field to people outside the program.

A variety of outreach activities for K-12 students take place throughout the year at the College as well as the schools locations, supported by faculty and students from the photonics program. These include visits to the College, summer camps, participation in Career Days organized by the schools, and other special events.

Middle school and high school students interested in STEM fields visit the College periodically. In 2015 we had 280 eighth grade students from four different schools coming to the College for a STEM day experience. Each school attended on a separate day. Students, divided into groups of 20, were introduced to several engineering and technology areas, with 30-40 minutes dedicated to each area. The general format of the sessions included a short, interactive presentation by faculty to introduce the area to students, followed by hands-on activities in the lab. The hands-on activities were specifically requested by the students' teachers and were much appreciated by the students.

For the photonics area, we started by presenting International Year of Light videos from SPIE and discussing the significance of the event. We encouraged students to learn more about IYL 2015 after the visit. Faculty explained what photonics is and discussed lasers, optical fibers and their wide spread applications in numerous fields today. For the hands-on activities we supplied each group with the following: red and green laser pointers, photometer to measure the optical power of the lasers, laser safety glasses, color filters, diffraction gratings (handheld spectrometers/diffraction glasses), prisms, and plastic optical fibers. Quick demos of how everything works were given, and then students were allowed to experiment by themselves. Faculty then asked the groups to share their findings and answered questions that came up.

Feedback from these sessions showed they were appropriate for eighth grade students who enjoyed them. For high school students who visited, the sessions had a similar format but a little bit more structured approach. Teachers requested to connect the topics presented to what students were learning in science and other courses. They also wanted more information to be provided about the career pathway a high school graduate can take to work in this field.

Summer camps were offered in 2015 to middle school and high school students separately. A record number of 45 middle school students attended the 5-day Robotics and Photonics summer camp, which included two half-days of photonics activities. We divided the large group in two and held a morning session and an afternoon session with the same content. The high school camp was titled "Exploring Engineering and Technology" and was attended by 25 students going into grades 9-12. A half-day session on photonics was held where students had the opportunity to perform a few experiments in the course of three hours. These included finding the speed of light in acrylic material, polarization, and diffraction grating experiments.

Faculty and students from Baker College also participated in two Career Day events for eighth grade students at two middle schools in the area. The entire eighth grade class at each school was exposed to photonics activities during these events. Similar to visits at the College, students were divided into groups and were involved in hands-on activities after an introduction to the field and to IYL 2015.

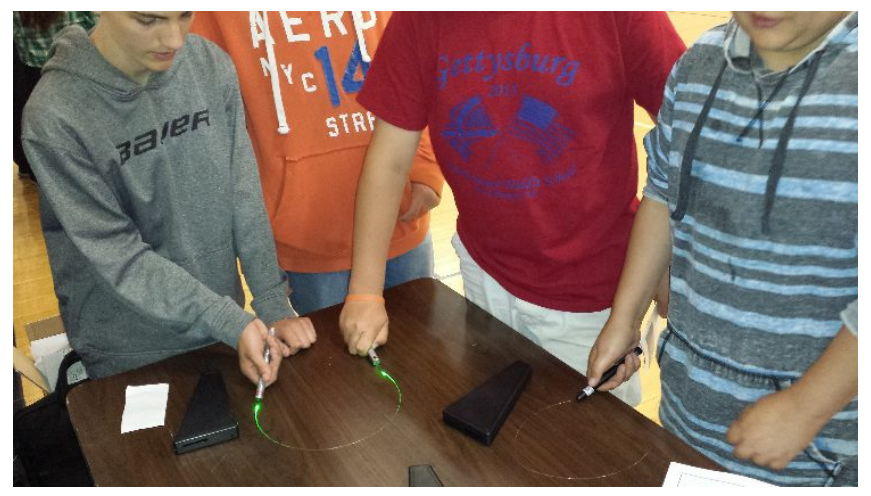

Fig. 3. Career Day at North Branch Middle School, June 2, 2015. 
The elementary school district in Grand Blanc, a suburb of Flint, organized a Family STEM Night in June 2015 that featured the International Year of Light and photonics activities. This was the first time we had an outreach event for elementary school students. Students came together with parents, siblings, and other family members who often participated in activities with their young kids.

\subsection{Back to the Bricks}

Another IYL event that reached a large number of people of all ages and backgrounds was the "Back to the Bricks" festival held in downtown Flint in August 2015. When it started several years ago, this event was mostly a car cruise through the central brick-paved boulevard, from which it derived its name. Over the years due in part to the large participation from the community, the organizers decided to bring other activities to the festival, so it became more than watching cars cruise by. An example are the many high school robotics teams from the area showing their competition robots. This expansion provided a wonderful opportunity to showcase optics and photonics to the general public under the auspices of the International Year of Light. For the first time, optics and photonics outreach was included in "Back to the Bricks" in 2015. The organizers provided us space for this purpose in a centrally located area in downtown Flint.

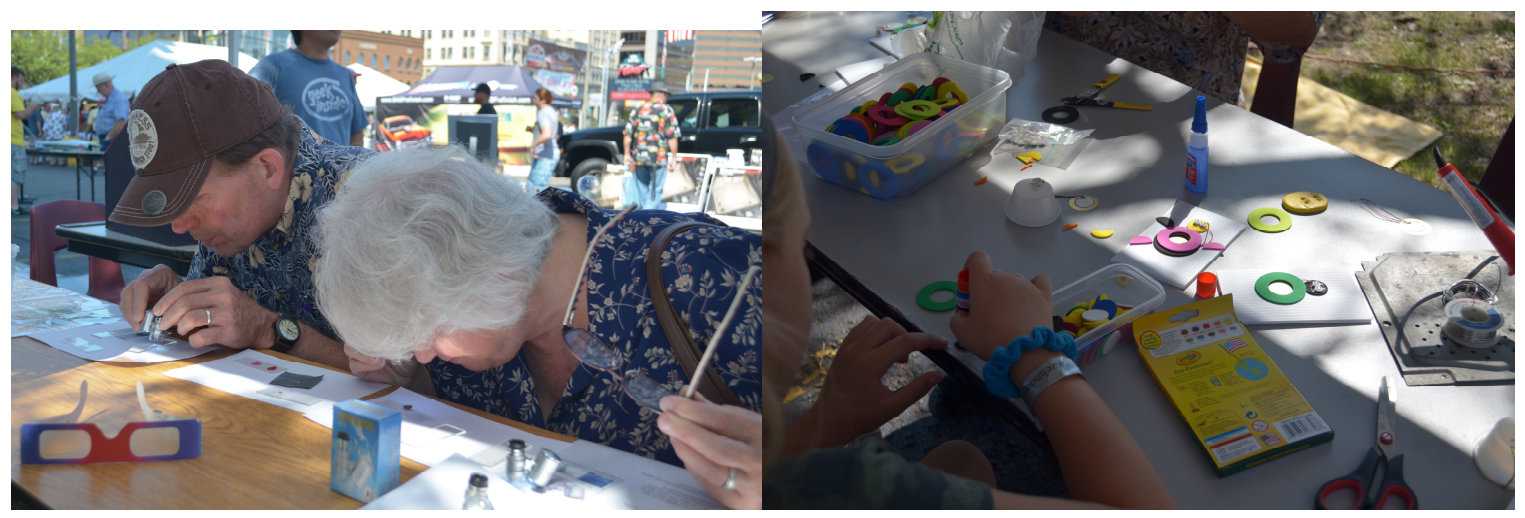

Fig. 4. (L) Married couple looking at samples with microscopes at Back to the Bricks on 15 August 2015. (R) Young girl creating a pinky-powered photon device. Note the LED eyes.

\section{RECOMMENDATIONS FOR BEST PRACTICES}

After the successful implementation of 16 events, we found the following to be the best practices.

\subsection{Fundraising}

When fundraising for outreach events, it is best to have a clear plan for which activities you want to undertake. Be prepared to explain how those activities benefit the community and your sponsor. We approached several local opticsrelated companies and asked for sponsorship.

\subsection{Logistics}

When planning a series of diverse outreach activities, we recommend that time is spent building relationships and understanding your groups unique constraints (time, money, space, etc.). For our group, we understood that due to our limited time and budget, it was best to collaborate with other organizations. By working together, we were able to gather more volunteers and plan better events. After polling our volunteers, we discovered that most were interested in volunteering for the events, but not engaging in the planning. Therefore, we relied heavily on activities that our representative groups already knew how to do. Furthermore, rather than plan our own events entirely, we collaborated with existing city festivals. This was effective because it saved us the time in planning and advertising as well as drew in people we would not otherwise have been able to contact.

\section{CONCLUSION}

A wide variety of outreach events took place in Michigan in 2015 to celebrate the International Year of Light. The events were possible through the collaboration and support of diverse groups and organizations, unified by a common 
passion for optics and photonics. Many of the activities put in place have continued in 2016 and it is the intent of the authors to make these sustainable activities for the future by leveraging the relationships developed during IYL 2015.

\section{ACKNOWLEDGEMENTS}

The authors would like to acknowledge the International Society for Optics and Photonics (SPIE), the Optical Society (OSA), Mi-Light, IPG-Photonics, and Thorlabs-UFO for their financial support of these activities. They would also like to acknowledge all of the volunteers that made these events possible, especially those from the Optical Society at the University of Michigan (OSUM), the Ann Arbor OSA, the Student Astronomical Society (SAS) at the University of Michigan, and Baker College of Flint. Furthermore, thank you to all of the festivals that let us participate and all of the people who stopped by our tables and enjoyed the wonder of light.

This paper is based upon work supported, in part, by the National Science Foundation Advanced Technological Education program, under Grant DUE \#1304071. Any opinions, findings, and conclusions or recommendations expressed in this material are those of the author and do not necessarily reflect the views of the National Science Foundation.

\section{REFERENCES}

[1] Sala, A., "Developing a photonics education program at college level from the ground up", SPIE Proceedings Vol. 9188, (2014), spie.org/Publications/Proceedings/Paper/10.1117/12.2061426

[2] OP-TEC, The National Center for Optics and Photonics Education, www.op-tec.org

[3] National Science Foundation Advanced Technological Education program, www.nsf.gov/funding/ pgm_summ.jsp?pims_id $=5464$

[4] Mi-Light, The Michigan Photonics Cluster, www.mi-light.org 